\title{
PERFORMANCE ASSESSMENT: KAJIAN BAGI EFEKTIVITAS PENINGKATAN PROFESIONALITAS GURU TEKNOLOGI DAN KEJURUAN
}

\author{
Zamtinah \\ Jurusan Pendidikan Teknik Elektro FT UNY \\ Email: zamtinahmarwan@yahoo.co.id
}

\begin{abstract}
Abstrak. Tanpa bermaksud mengesampingkan faktor determinan lain, guru diakui sebagai faktor sentral atas keberhasilan kualitas pendidikan, bahkan Davies \& Ellison (1992) menyebut guru sebagai key person in the classroom. Oleh sebab itu sangatlah wajar jika guru dituntut profesional di dalam menjalankan tugasnya, dan untuk mengetahui bagaimana profesionalitas seorang guru perlu dilakukan penilaian yang efektif agar diperoleh hasil yang efektif pula. Tulisan ini bertujuan untuk mengkaji bagaimana efektivitas Performance Assessment sebagai sarana peningkatan profesionalitas guru teknologi dan kejuruan? Bagaimana ciri-ciri guru teknologi dan kejuruan yang profesional?. Metode yang digunakan dalam penulisan artikel ini adalah melalui kajian terhadap hasil studi yang pernah dilakukan, melalui riset kepustakaan, dan analisis kritis terhadap konsepkonsep Performance Assessment, dan mengkaji kriteria guru yang professional. Hasil kajian menunjukkan bahwa Performance Assessment secara konseptual mampu meningkatkan profesionalitas guru teknologi dan kejuruan. Hal ini disebabkan karena Performance Assessment dianggap lebih otentik, penilaiannya lebih mencerminkan kemampuan yang sebenarnya. Kajian ini juga mampu mendiskripsikan bagaimana kriteria guru teknologi dan kejuruan yang professional.
\end{abstract}

Kata kunci: performance assessment, profesionalitas guru

\begin{abstract}
Without meaning to the exclusion of other determinant factors, the teacher is recognized as a central factor for the success of the quality of education, even Davies \& Ellison (1992) mention to teachers as key person in the classroom. Therefore it is natural that teachers are required in carrying out its duties professionally. This paper aims to examine how the effectiveness of the Performance Assessment as a means of improving the professionalism of vocational and technology teacher. How do the characteristics of the professionality of the teacher of technology and vocational. The method used in the writing of this article is through the study of the results of studies that have been conducted, through library research, and critical analysis of the concepts of Performance Assessment, and reviewing professional teacher criteria. The results of the study showed that the Performance Assessment is conceptually able to increase the professionalism of the teacher of technology and vocational. This is because the Performance Assessment is considered more authentic, more reflects actual capabilities. This study was also able to describe how the criteria of the teacher of technology and vocational.
\end{abstract}

Keywords: performance assessment, teacher professionality

\section{PENDAHULUAN}

Secara epistimologis, makna kata guru begitu tinggi dan sangatlah terhormat. Kata 'guru' berasal dari bahasa Sanskerta, gur-ứ, yang berarti mulia, bermutu, mempunyai kehebatan, dan pantas untuk dihormati. Guru diasosiasikan sebagai sosok yang harus menjadi suri tauladan, reflektif, tidak boleh memiliki cela dan tidak boleh melakukan kesalahan. Melalui jarwo dhoso bahasa Jawa, guru dimaknai sebagai figur yang harus digugu lan ditiru, artinya, guru adalah 
orang yang selalu diikuti, ditaati, dan ditiru perilakunya. Apapun yang dilakukan guru, senantiasa akan diteladani oleh murid-muridnya.

Namun sayang, anggapan terhadap kemuliaan dan keluhuran budi sosok guru sebagaimana uraian di atas, nampaknya terjadi pergeseran di era global seperti saat ini. Demonstrasi guru dalam rangka menuntut hak-haknya tetapi sekaligus mengabaikan kewajiban mengajar, yang dahulu kala dapat dikatakan 'tabu' dilakukan guru, akan tetapi saat ini dianggap wajar. Ini merupakan salah satu contoh dari pergeseran tersebut, belum lagi contoh tindakan asusila yang sering dilakukan oleh oknum guru. Padahal secara pemenuhan kebutuhan dan kesejahteraan guru justru lebih diperhatikan pada era sekarang daripada jaman dulu. Pertanyaannya sekarang adalah, ada apa dengan pengabdian dan ketulusan guru, mengapa guru sekarang cenderung komersil dalam mendidik muridmuridnya. Bagaimana dengan pembinaan guru, apakah ada yang salah dalam rekrutmen guru, apakah ada yang tidak tepat dengan pola evaluasi kinerja guru? Bagaimana meningkatkan profesionalitas guru tanpa mengabaikan aspek budi pekerti dan keteladanan guru? Tulisan ini akan mengkaji pola evaluasi melalui Performance Asessment dalam rangka meningkatkan profesionalitas guru, khususnya guru kejuruan dan teknologi.

Selain UU No.14 Tahun 2005, masalah profesionalitas guru juga diatur di dalam Undang Undang Sisdiknas (UU No. 20 Tahun 2003) yang mengamanatkan kepada pendidik terutama guru agar berubah menuju terjadinya profesionalisme, misalnya pada Pasal 40 Ayat (2) dijelaskan bahwa pendidik atau guru berkewajiban:

"menciptakan suasana pendidikan yang bermakna, menyenangkan, kreatif, dinamis, dan dialogis; mempunyai komitmen secara profesional untuk meningkatkan mutu pendidikan; dan memberi teladan dan menjaga nama baik lembaga, profesi, dan kedudukan sesuai dengan kepercayaan yang diberikan kepadanya"

Berdasarkan pasal tersebut tersirat bahwa tuntutan profesionalisme guru harus sejalan dengan tuntutan era global serta perkembangan ilmu pengetahuan dan teknologi. Jika guru tidak diarahkan dan mau berubah menuju profesionalisme, maka akan ketinggalan dan ditinggalkan oleh stakeholder-nya 
(siswa, pimpinan, keluarga, dan masyarakat yang lebih luas). Selanjutnya kalau hal ini terjadi pada mayoritas pendidik atau guru, maka akan menjadi beban bagi berlangsungnya proses pendidikan.

Di dalam konteks pemberdayaan pendidikan, aspek profesionalisme guru antara lain mencakup persoalan kepemimpinan, ketrampilan profesional untuk mewujudkan sekolah yang efektif, serta ketrampilan profesional dalam proses pembelajaran. (Suyanto, 2006). Lebih lanjut Suyanto menyatakan bahwa, guru yang efektif akan menciptakan pembelajaran yang efektif. Efek domino dari pembelajaran efektif adalah terwujudnya sekolah yang efektif. Apabila dari keseluruhan sekolah telah efektif, maka system pendidikan nasional juga akan efektif. Efektif disini dimaknai pada tercapainya tujuan pendidikan, baik pada skala mikro maupun makro.

Sebagaimana dikutip oleh Susmono La Ode (2010), salah satu jurnal di Amerika Serikat, Jurnal Educational Leadership tahun 1993, menjelaskan bahwa untuk menjadi profesional, seorang guru dituntut memiliki lima hal, yaitu: 1) guru mempunyai komitmen pada siswa dan proses pembelajarannya; 2) Guru menguasai secara mendalam mata pelajaran yang diajarkannya dan metode mengajarnya kepada siswa; 3) Guru bertanggungjawab memantau hasil belajar siswanya melalui berbagai cara evaluasi; 4) Guru mampu berfikir sistematis tentang apa yang dilakukannya dan belajar dari pengalamannya; 5) Guru seyogyanya merupakan bagian dari masyarakat belajar dalam lingkungan profesinya.

Menurut Dedi Supriadi, profesionalisme seorang guru merupakan hasil dari profesionalisasi yang dijalaninya secara terus menerus, diantaranya pendidikan pra-jabatan (pre-service education), pendidikan dalam jabatan termasuk penataran (in-service training), pembinan dari organisasi profesi dan tempat kerja, penghargaan masyarakat terhadap profesi guru, penegakan kode etik, sertifikasi, peningkatan kualitas calon guru dan sebagainya (1999).

Secara umum, tuntutan profesionalitas guru SMK tidak jauh berbeda dengan guru pada umumnya seperti guru SMU. Yangmembedakan adalah bahwa materi pembelajaran di SMK lebih dominan pada aspek psikomotorik, sehingga pembelajaran dan tuntutan guru SMK sedikit berbeda. 
Sekolah Menengah Kejuruan (SMK) berdasarkan pedoman dalam sistem pendidikan nasional adalah pendidikan yang mengutamakan pengembangan kemampuan siswa untuk melaksanakan jenis-jenis pekerjaan tertentu (Pasal 15 Undang Undang no : 20 tahun 2003 tentang Sistem Pendidikan Nasional). Sementara Mulyasa (2002) menyebutkan bahwa pendidikan kejuruan sebagai pendidikan yang memberikan bekal kepada peserta didik untuk dapat bekerja guna menopang kehidupannya. Tujuan SMK adalah: 1) Mewujudkan Lembaga Pendidikan Kejuruan yang akuntabel sebagai Pusar Pembudayaan Kompetensi Berstandar Nasional; 2) Mendidik Sumber Daya Manusia yang mempunyai etos kerja dan kompetensi berstandar internasional; 3) Memberikan berbagai layanan Pendidikan Kejuruan yang permeabel dan flesibel secara terintegrasi antara jalur dan jenjang pendidikan ; 4) Memperluas layanan dan pemerataan mutu pendidikan kejuruan; 5) Mengangkat keunggulan lokal sebagai modal daya saing bangsa.

Menurut Djemari Mardapi (2000) performance assessment atau asesmen kinerja merupakan penilaian terhadap proses perolehan, penerapan pengetahuan, dan keterampilan melalui proses pembelajaran yang menunjukkan kemampuan siswa dalam proses maupun produk. Salah satu asesmen yang banyak digunakan dalam menentukan kemampuan seseorang adalah asesmen kinerja. Hal ini disebabkan karena penilaian kinerja dianggap lebih otentik, penilaiannya lebih mencerminkan kemampuan siswa yang sebenarnya.

Definisi asesmen kinerja (performance assessment) menurut Berk (1986) adalah "Performance assessment is the process of gathering data by systematic observation for making decisions about an individual" yang maksudnya adalah bahwa penilaian kinerja merupakan proses pengumpulan data melalui observasi sistematik untuk membuat kebijakan bagi seorang individu. Lebih lanjut Berk menyatakan bahwa terdapat lima elemen kunci di dalam definisi tersebut, yaitu: 1) penilaian kinerja adalah sebuah proses, bukan merupakan sebuah tes atau perangkat instrumen tunggal; 2) fokus dari proses penilaian adalah pada pengumpulan data dengan menggunakan instrumen dan strategi yang bervariasi; 3) data dikumpulkan dengan alat observasi sistematik; 4) data diintegrasikan pada tujuan pembuatan kebijakan spesifik yang digunakan sebagai panduan substansi 
penilaian; 5) subyek dari pembuatan kebijakan adalah seorang individu yang biasanya seorang pekerja atau siswa, bukan suatu program atau produk yang merefleksikan aktivitas sekelompok orang.

Menurut Fitzpatrick dan Morrison (dalam Johnson, et.al, 2009), performens (kinerja) merupakan rangkaian respons yang ditujukan pada modifikasi lingkungan dengan cara-cara spesifik. Rangkaian respons tersebut mencakup perilaku peserta ujian, yang dikatakan, dan dikreasi oleh peserta ujian. Dengan demikian istilah kinerja dimaksudkan sebagai perilaku atau tindakan, sebuah ide dan eksekusi sederhana untuk melakukan pekerjaan. Lebih lanjut dinyatakan bahwa dalam penilaian kinerja, peserta ujian menunjukkan pengetahuan dan keterampilan mereka dengan terlibat dalam proses atau membangun suatu produk. Lebih luas lagi, penilaian kinerja adalah suatu sistem yang terdiri dari (1) tujuan penilaian, (2) tugas (atau petunjuk) yang menimbulkan kinerja, (3) permintaan respon yang berfokus kinerja peserta ujian, dan (4) metode sistematis untuk penilaian kinerja (Ruiz-Primo \& Shavelson, 1996; Shavelson, Solano-Flores, \& Ruiz-Primo, 1998; Stiggins, 1987a dalam Johnson, et.al, 2009).

Dari ketiga definisi tersebut dapat disimpulkan bahwa penilaian kinerja merupakan penilaian terhadap kinerja seseorang mencakup proses perolehan, penerapan pengetahuan, dan keterampilan melalui proses pembelajaran yang menunjukkan kemampuan, didokumentasikan melalui observasi yang sistematik untuk menetapkan kebijakan terhadap orang tersebut, apakah siswa ataupun seorang pekerja yang berkompeten terhadap suatu pekerjaan.

Terdapat perbedaan orientasi dan metodologi penilaian kinerja antara penilaian terhadap siswa di sekolah dengan subyek yang sudah bekerja. Tabel 1 mengilustrasikan perbedaan tersebut. Kualitas yang perlu diperhatikan dalam penggunaan penilaian kinerja meliputi (1) keaslian, (2) konteks, (3) kompleksitas kognitif, (4) secara mendalam cakupan tenda, (5) respons terperiksa-terstruktur, (6) kredibilitas, (7) biaya, dan (8) reformasi (Lane \& Stone, 2006; Linn, Baker, \& Dunbar, 1991; Wiggins, 1992 dalam Johnson et.al, 2009) 
Tabel 1. Determinan utama metodologi penilaian kinerja

\begin{tabular}{|c|c|c|}
\hline \multirow{2}{*}{ Determinan } & \multicolumn{2}{|c|}{ Subyek Penilaian } \\
\hline & Pekerja & Siswa \\
\hline $\begin{array}{l}\text { Tujuan } \\
\text { Penilaian }\end{array}$ & $\begin{array}{l}\text { Untuk menentukan level kinerja } \\
\text { atau kompetensi (dengan kriteria } \\
\text { sukses versus tidak sukses) }\end{array}$ & $\begin{array}{l}\text { Untuk menentukan level kinerja } \\
\text { siswa (capaian tinggi versus } \\
\text { capaian rendah; master versus } \\
\text { nonmaster) }\end{array}$ \\
\hline Kebijakan & $\begin{array}{l}\text { Seleksi } \\
\text { Promosi } \\
\text { Retensi (hak tetap memiliki) } \\
\text { Demosi (Penurunan Pangkat) } \\
\text { Transfer } \\
\text { Terminasi } \\
\text { Perbaikan upah }\end{array}$ & $\begin{array}{l}\text { Screening } \\
\text { Diagnosis } \\
\text { Klasifikasi/Penempatan } \\
\text { Formatif } \\
\text { Sumatif }\end{array}$ \\
\hline Tindakan & $\begin{array}{l}\text { Bimbingan untuk meningkatkan } \\
\text { motivasi kerja } \\
\text { Pelatihan untuk meningkatkan } \\
\text { keterampilan }\end{array}$ & $\begin{array}{l}\text { Penentuan program pengajaran } \\
\text { dan tindakan yang sesuai. } \\
\text { Sertifikasi kompetensi } \\
\text { Lisensi }\end{array}$ \\
\hline $\begin{array}{l}\text { Metode } \\
\text { Penilaian }\end{array}$ & $\begin{array}{l}\text { Functional Job analysis (FJA), N } \\
\text { Test, Assessment Center, Apprai } \\
\text { Validity Generalatization and Pre } \\
\text { Distribution Assessment }\end{array}$ & $\begin{array}{l}\text { erical Rating Scale, Performance } \\
\text { Interview, Utulity Analysis, } \\
\text { ctive Bias, Performance }\end{array}$ \\
\hline
\end{tabular}

Di antara faktor-faktor penentu utama metodologi penilaian kinerja yang tercantum dalam tabel 1, adalah sifat dari keputusan yang membedakan antara penilaian kinerja terhadap karyawan dan terhadap siswa. Langkah pertama dalam proses penilaian adalah menentukan keputusan individu yang akan dibuat. Langkah berikutnya adalah menyesuaikan strategi pengukuran dan pengumpulan data sehingga diperoleh informasi penting bagi keputusan mereka.

Selain keputusan yang diberikan sesuai dengan hasil penilaian, level tertentu dari kinerja individu menunjukkan bahwa tindakan tertentu harus diambil. Ketika kinerja karyawan dinilai tidak memuaskan, keputusan untuk menurunkan atau mempertahankan dapat dicapai dengan rekomendasi untuk melatih karyawan agar keterampilannya meningkat. Keputusan instruksional dari tes diagnostik dan formatif berdasarkan tingkat kinerja siswa biasanya diikuti dengan solusi dengan menunjuk bahan ajar yang sesuai. Sertifikat atau lisensi dapat diterbitkan jika tingkat kriteria dalam program professional telah tercapai. Semua tindakan ini dapat dilihat sebagai konsekuensi dari proses pengambilan keputusan dan, dengan 
demikian, harus dipertimbangkan dalam hubungannya dengan keputusan dalam perencanaan penilaian.

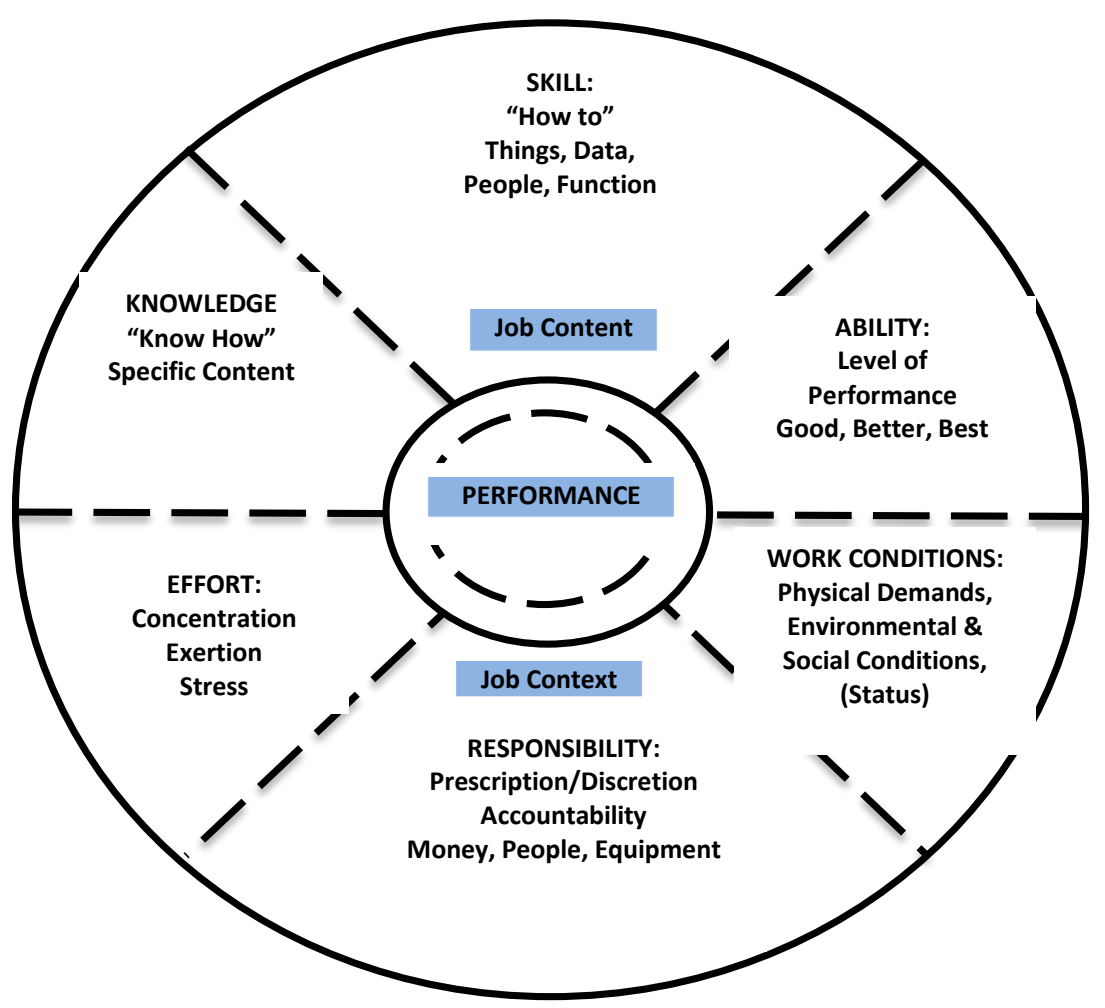

Gambar 1. Konsep holistik penilaian kinerja (Sumber: Berk, 1986)

Gambar 1 menggambarkan proses dari keseluruhan kinerja. Pada titik pusat adalah kinerja yang belum dianalisis. Kinerja secara holistik dari orang yang melakukan pekerjaan mereka. Mungkin para pekerja tidak melakukan pekerjaannya dengan cukup baik dan mereka perlu bantuan agar bisa lebih baik. Istilah sehari-hari tentang "pengetahuan", "keterampilan", "kemampuan", "usaha", "tanggung jawab", dan "kondisi kerja" akan muncul dan digunakan untuk komunikasi ini. Pengetahuan, keterampilan, dan kemampuan memiliki hubungan langsung dengan isi pekerjaan atau output dari pekerjaan. Usaha, tanggung jawab, dan kondisi kerja lebih berhubungan dengan situasi atau konteks environtmental pekerjaan yang pekerja individu harus beradaptasi.

Gambar 1 juga memberikan gambaran bahwa pengetahuan berhubungan dengan konten spesifik tentang "bagaimana tahu" meliputi materi, produk, materi pelajaran, atau layanan, teknologi, prosedur asli, mesin-mesin, peralatan, perlengkapan, atau bantu kerja. Pengetahuan dinyatakan sebagai kata benda. 
Keterampilan berhubungan dengan "bagaimana" berdasar pada fungsi, data, dan hierarki seseorang dari analisis jabatan fungsional. Kemampuan berhubungan dengan kualitas (kata sifat atau kata keterangan) atau jumlah (angka) yang perlu dicapai oleh pekerja untuk menghasilkan output yang memuaskan. Usaha efforts) mengacu pada konsentrasi (mental), atau stres (emosional) yang tampaknya akan diperlukan dalam situasi kerja. Tanggung jawab mengacu pada perpaduan preskripsi/diskresi dalam instruksi dan juga sebagai konsekuensi keterlibatan mereka dalam pekerjaan. Kondisi kerja berhubungan dengan kebutuhan fisik, lingkungan, dan kondisi sosial.

Guru yang efektif akan menghasilkan pembelajaran yang efektif. Pembelajaran yang efektif akan meningkatkan efektivitas pendidikan secara makro. Pembelajaran yang efektif dapat diwujudkan jika para guru sebagai garda terdepan system pembelajaran di kelas memiliki profesionalitas yang dipersyaratkan.

Selanjutnya dalam rangka pembinaan dan peningkatan profesionalitas guru, secara perodik dievaluasi oleh pihak yang memiliki otoritas mengevaluasi, menilai atau meng-ases kinerja guru. Terdapat berbagai macam system evaluai atau asesmen terhadap profesionalitas guru, diantaranya penilaian portofolio sebagaimana yang pernah dilakukan beberapa waktu yang lalu. Penilaian portofolio ini memiliki beberapa kelemahan, di antaranya rawan manipulasi terdapat bukti atau evidens yang ditunjukkan guru. Selain itu juga juga kinerja guru tidak dapat secara komprehensif diketahui. System penilaian lainnya dapat melalui tes, maupun melalui penilaian kinerja.

Penilaian kinerja (Assessment Performance) terhadap guru diharapkan efektif meningkatkan profesionalitas guru karena yang dinilai bukan semata-mata dokumen tertulis yang dimiliki guru, tetapi kemampuan guru dari berbagai aspek langsung dipraktikkan oleh guru. Dengan demikian kekahwatitan beberapa pihak terhadap praktik manipulasi dokumen portofolio dapat diatasi, karena yang dinilai adalah lngsung pada kompetensi guru.

Untuk mendapatkan penilaian yang kredibel, selain instrument penilaian yang kredibel, juga dibutuhkan penilai (asesor) yang kredibel pula. Menurut RussEft et.al (200), kriteria asesor yang kredibel adalah memiliki: 1) Professional 
foundations and competence (communicate accurately and effectively, observe ethical standards, obtain and maintain needed skills, understand evaluation background and history); 2) Professional responsibility, integrity, and accountability (accurately reprens skills, disclose conflict of interest, negotiate honestly, communicate accurately and fairly, understand polotics); 3) Respect for people (use informed consent, maintain confidentiality, maximize benefit and reduce harm, communicate respect for stakeholders, understand multicultural and cross-cultural aspects); 4) Social responsibility mencakup aspek consider wider implications and side effects, recognize obligations for public good;

\section{KESIMPULAN}

Guru yang efektif akan menghasilkan pembelajaran yang efektif. Pembelajaran yang efektif akan meningkatkan efektivitas pendidikan secara makro. Pembelajaran yang efektif dapat diwujudkan jika para guru sebagai garda terdepan system pembelajaran di kelas memiliki profesionalitas yang dipersyaratkan.

Salah satu sistem evaluasi yang efektif meningkatkan profesionalitas guru adalah performance assessment, yang menurut beberapa ahli didefinisikan sebagai penilaian terhadap kinerja seseorang mencakup proses perolehan, penerapan pengetahuan, dan keterampilan melalui proses pembelajaran yang menunjukkan kemampuan, didokumentasikan melalui observasi yang sistematik untuk menetapkan kebijakan terhadap orang tersebut.

Untuk mendapatkan hasil penilaian yang kredibel terhadap profesionalitas guru, selain instrumen penilaian kinerja guru yang kredibel, juga dibutuhkan penilai (asesor) yang kredibel pula. Asesor tersebut harus memiliki: 1) Professional foundations and competence (communicate accurately and effectively, observe ethical standards, obtain and maintain needed skills, understand evaluation background and history); 2) Professional responsibility, integrity, and accountability (accurately reprens skills, disclose conflict of interest, negotiate honestly, communicate accurately and fairly, understand politics); 3) Respect for people (use informed consent, maintain confidentiality, maximize benefit and reduce harm, communicate respect for stakeholders, 
understand multicultural and cross-cultural aspects); 4) Social responsibility mencakup aspek consider wider implications and side effects, recognize obligations for public good;

\section{DAFTAR PUSTAKA}

Berk, Ronald A. (1986). Performance Assessment Methods \& Applications. Baltomore \& London: The Johns Hopkins University Press.

Brandt,R. (1993). “What Do You Mean Proffesional? Educational Leadership No.6 March.

Davies dan Ellison (1992) dalam Menjadi guru sejati (Sismono Laode, 2010) Yogyakarta: UNY Press.

Dedi Supriadi (19990. Mengangkat Citra dan Martabat Guru. Bandung: Adicita Karya Nusa.

Djemari Mardapi (Mei 2000) Konsep Dasar asesmen kinerja. Maklah seminar pengembangan penilaian kinerja, LPPM UNY

Johnson,D.W. \& Johnson, R.T.(20020 Meaningful assessment a manageable an cooperative process. Boston: Allyn and Beacon

Direktorat Pembinaan SMK, Dirjen MPDM. Depdiknas.2008. Garis-Garis Besar Program Pembinaan SMK Tahun 2008

Mulyasa. 2002. Kurikulum Berbasis Kompetensi. Bandung : PT. Remaja Rosdakarya.

Sismono La Ode, dkk.(2010). Wasiat Prof. Sugeng Mardiyono, Pd.D. Menjadi Guru Sejati. Yogyakarta: UNY Press.

Suyanto. (2006). Dinamika Pendidikan Nasional (Dalam Percaturan Global). Jakarta: PSAP Muhammadiyah

2007. Garis-garis Besar Program SMK 2007. Jakarta : Direktorat Pembinaan SMK Direktorat Jenderal Manajemen Pendidikan Dasar dan Menengah Departemen Pendidikan Nasional

Undang Undang Republik Indonesia tentang Sistim Pendidikan Nasional.

Undang-Undang No. 14 Tahun 2005 Tentang Guru dan Dosen 